\title{
Digital Value-Added Services: Recommendations for Early Development
}

\author{
Christian Matt \\ University of Bern \\ christian.matt@iwi.unibe.ch \\ Michael Dowling \\ University of Regensburg \\ michael.dowling@wiwi.uni-regensburg.de
}

\author{
Markus Huppatz \\ University of Regensburg \\ markus.huppatz@wiwi.uni-regensburg.de
}

\author{
Thomas Hess \\ LMU Munich \\ thess@bwl.lmu.de
}

\begin{abstract}
Digital value-added services (DVAS) represent a major opportunity for firms to create additional value for customers and differentiate themselves from competitors. However, many firms are struggling with how to develop DVAS. They often hire specialized innovation consulting firms to do this job but we know little about their secrets of success. To shed more light on the topic, we collected best practices along the critical first steps of DVAS development and derived six recommendations that can help firms increase their success rates. We provide insights, particularly concerning underlying organizational processes, the conception of ideas and the integration of customers.
\end{abstract}

\section{Introduction}

In recent years, many companies across industries have used digital technologies (DTs) to extend their core product offering by developing value-added services along different points of the customer journey. Only considering the market for commercial lines insurance, the potential global impact of valueadded services is estimated approximately 2 billion USD [7]. We focus on "digital value-added services (DVAS)", which are often marketed separately (usually for free) and serve as a digital add-on to the actual (often still physical) core offerings of a company. For instance, customers of most airlines can nowadays use dedicated smartphone apps to check-in for their flights or find the way to the nearest lounge prior to a flight. At the gate, the same app can be used to obtain up-to-date information about the flight status and boarding passes. After the flight, the app provides them with information about baggage claim locations or sightseeing tips. Car manufacturers such as Audi and furniture shops like IKEA use the most recent advances in virtual reality to offer customers DVAS that provide the possibility of inspecting their products in 3D from anywhere, before even entering a shop. All of these examples show that with the help of DTs, such as locationbased services, real-time analytics and virtual reality, companies can develop DVAS that differentiate them from competitors and increase customer value, loyalty and/or willingness-to-pay [22]. Digital in that sense does not just refer to the digitization of previously analog service offerings, it comprises the use of DTs to enable, support or offer corporate products or service based on an integrated concept and with potentially large effects on processes or even entire business models [15]. For DVAS, instead of concentrating on the core product offering alone, firms now often focus on a multi-layered productservice package that enables them to extend their value proposition along all phases of the customer relationship.

However, expanding a core product offering with additional digital services is not an easy task, especially if the underlying main product or service is complex [13]. Overall, it is estimated that $80-90 \%$ of all innovation projects fail - many of them already in the first stages [12]. Concerning innovation of mobile services, some studies even claim there has been a "European Failure", since most innovations in this field now come from outside Europe [24]. Failure rates for DVAS are not likely to be lower due to high technological requirements, separate marketing efforts and the customer support that is often required. In contrast to analog products or services, developing DVAS often requires distinct capabilities and techniques. In addition, outdated organizational structures and a lack of creativity pose substantial hurdles for the development of DVAS. Last, the number of similar concepts being discussed in practice, such as servitization, product-servicesystems and hybrid products, make it even more difficult for firms to understand what kind of options they have and what requirements they need to fulfill 
when developing DVAS. To address these issues, many companies rely on specialized external consulting firms for DVAS development but little is known about how such "innovation experts" proceed. To gain rich insights into the process and provide recommendations to companies who seek to launch such innovation projects themselves, we conducted case studies of DVAS developed by consulting firms at the "fuzzy front-end" for client firms. The fuzzy front-end of the innovation process is particularly difficult to manage since it is characterized by high levels of uncertainty, and therefore we focus on it. Based on data from 19 in-depth interviews, we derive six recommendations for success factors concerning the implementation of these early phases of innovation. We believe that our recommendations will help firms to improve DVAS development and therefore help them expand their current core product offerings to provide more value to their customers.

\section{Conceptual Background}

\subsection{What Makes Digital Value-Added Services Unique}

There are many different ways that firms can use DVAS to enrich or combine products and services. Firms must take the characteristics of their current core offerings, their corporate technological knowhow and other factors into account to choose between pure products, pure services and more or less integrated combinations of both. To provide more clarity about how DVAS relate to other forms of products and services, we establish a framework consisting of a continuum from pure products to pure services (Figure 1).

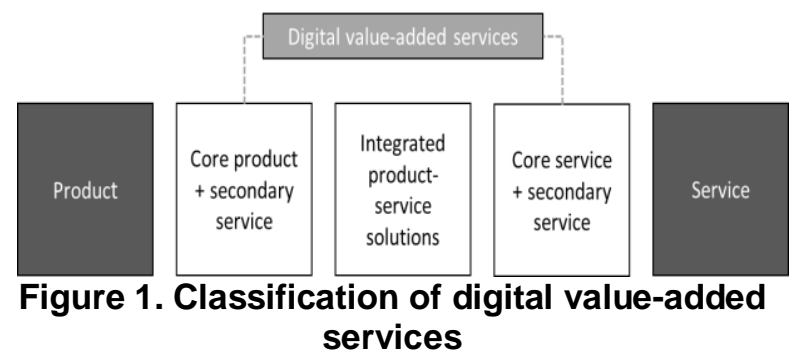

- Pure products and services: The two original forms of offerings are located at the outer extreme points of the continuum and they represent a pure product- or service-based core offering without any specific service extensions. Such cases still exist but are becoming less frequent since many companies nowadays are exploiting DTs to offer additional services.

- Integrated product-service solutions: These are bundles of a core product or service and additional service components characterized by the close integration and connection of the individual components. In fact, a clear separation between product and service is no longer possible. Instead, these offerings are sold as integrated solutions. These include different productservice-systems, smart products, or hybrid products.

- Core product/service and secondary service: These represent service extensions that still allow for a clear division into primary product or service and secondary services: The core product or service has one or several digital services along the customer journey. DVAS comprise this category since they are not directly bundled with their corresponding core product or service but provide add-on services.

Our research focuses on DVAS also because of their substantial business impact [7], yet there has not been much research conducted about them. At the same time, DVAS differ substantially from other traditional service extensions in several important ways. First, existing approaches to add-on services focus primarily on services that are marketed and priced at the point of sale as bundles of the core product and secondary services [2]. In contrast, DVAS are provided during the entire customer relationship - before, during and after the purchase of the core product. They are marketed and offered separately from the core offering and are generally free. Second, the supplementary services discussed in the literature are often based on "analog" add-on services, for which employees provide additional services to customers, or they represent service expansions for traditional industrial goods [18]. Therefore, DVAS possess distinct characteristics that limit the transfer of previous research from other domains. However, the innovation phases for DVAS are comparable to other service innovation projects and we focus on the first phases owing to their substantial challenges.

\subsection{The Critical First Phases of Service Innovation}

Innovation processes are often divided in two main stages: The so called "fuzzy front-end" comprises strategic and conceptual activities, whereas the execution-oriented "back-end" is focused 
more on implementing and marketing [23]. We focus on the fuzzy front-end, which is characterized by rather unstructured, experimental methods and higher chances of ideas being rejected, and which is seen as particularly relevant for innovation success. The greatest differences between winners and losers in product development are found in the quality of their pre-development activities [11]. While only accounting for a minor share of the overall innovation cost, the fuzzy front-end is often characterized by high market and technological uncertainties. Due to its leverage effects, a major share of the product lifecycle costs and the quality of the innovation are determined in the front-end [5]. For instance, if customer demands and technical specifications of a new product are unclear, the required changes in the later process become very costly and time intensive and market launches might be delayed. On the other hand, well-designed early innovation phases can lead to a better allocation of resources, risk reduction and lower subsequent costs [23]. Top management should actively design the activities in the first phases of innovation, divided into (1) Opportunity Identification, (2) Ideation and Valuation and (3) Concept Development and Testing [14]. The underlying innovation process organization is another important aspect that has effects on all of the aforementioned core activities (Figure 2).

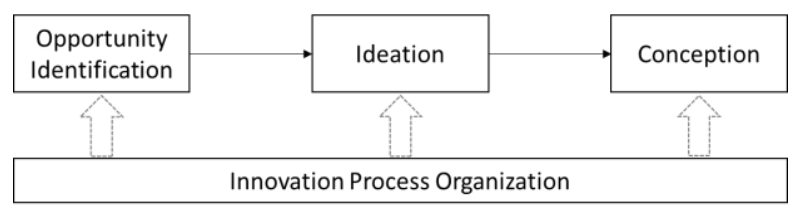

Figure 2. The fuzzy front-end of innovation

\section{Research Methodology and Sample}

For our research, we used the case study approach as it enables us to study "contemporary phenomenon in depth and within its real-life context, especially when the boundaries between the phenomenon and context are not clearly evident" [25]. Further, the research questions we raised were generally "how"questions, which are particularly suitable for case studies. We have chosen several cases in a multiple case study design which provide higher generalizability in comparison to a single case study design. To account for industry-specific factors, our study uses exemplary innovation projects from different industries, which we selected in a two-stage approach. First, we searched for B2C companies offering digital value-added services to their end customers and included companies from the service sector as well as from the product manufacturing sector. In a second step, we conducted several expert interviews in order to identify five innovative and representative cases. Based on these interviews, we conducted semi-structured interviews with employees from innovation consulting firms that were involved in these projects. The semi-structured interviews served as the primary source of data collection. We used additional data sources to triangulate the results. For example, one of the authors directly observed some of the projects to better understand the development process of DVAS. We also used other sources such as books, documents and presentations to supplement the 19 interviews that we conducted. Each of the interviews lasted between one to three hours and followed a general outline but were adapted interactively based on interviewees' reasoning and the aspects mentioned. Interviewees were directly involved in the innovation projects and held different senior positions at the innovation consulting firms, ranging from designers, strategists to management. Appendix 1 presents an overview of the innovation consulting firms and their staff that we interviewed. Appendix 2 provides more details about the concrete DVAS development projects.

\section{Deriving Recommendations on DVAS Development}

\subsection{Innovation Process Organization}

The appropriate organizational structure for innovation projects is an important issue, especially for the front-end development, when uncertainty and complexity is high. Two levels need to be considered: the general organization of the focal firm that conducts the innovation and the project-specific organization for the development of DVAS. For the latter, we found that the innovation consulting firms used a similar organizational structure for DVAS development projects. This structure is linked to the key areas of technical expertise that the consulting firms offer their clients. Five general competence areas can be distinguished (Figure 3):

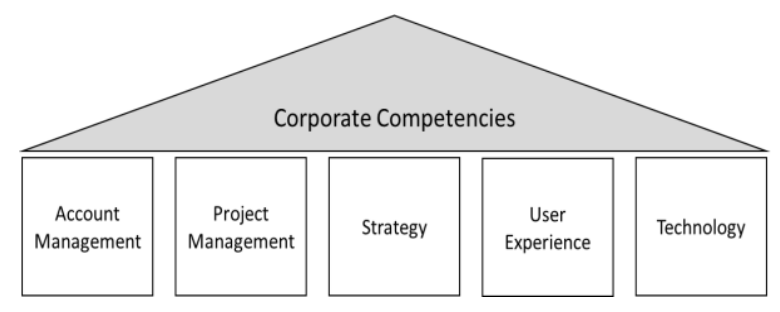

Figure 3. Typical organizational setup of innovation consultancies 
- Account Management: Account managers are responsible for building a long-term relationship with the clients of the innovation consulting firms. Account managers serve as the primary contact point for clients and have a deep understanding of their industry and business model.

- Project Management: Project managers are responsible for the overall planning, steering and monitoring of the innovation projects.

- Strategy: Strategists are responsible for developing an integrated long-term strategy based on a client's problem statement. Strategists integrate customer requirements, business needs and technological opportunities into a comprehensive picture.

- User Experience: Managers in this competence area are responsible for the structural and visual design of the developed solution.

- Technology: Technology staff are responsible for the design of the system architecture and the technical implementation of the developed solution.

Since the innovation consulting companies act as distinct firms, they are different from focal firms that might also conduct in-house innovation projects. Hence, some of the project-based functions are likely to merge with other existing corporate structures. However, we believe that this general structure is valuable to most firms, especially for the larger ones that have dedicated innovation units.

R1: Firms should use account management, project management, strategy, user experience and technology as common functions for their innovation project organization.

Critics argue that classical Stage-Gate innovation models, that are still applied in many companies today, are too linear and too rigid to adequately handle more radical and dynamic innovation projects [16]. Digital innovations often occur in a different context than conventional tangible goods and thus require distinct development processes. Agile development methods, originally invented for software development, have become very popular in recent years. Such methods are more flexible, concerning changes in customer preferences as well as technical requirements during development, which might not be completely predictable in advance. By dividing the overall project into short iterations, agile methods allow for short planning cycles, the early involvement of end-users, flexible requirements management and reduced documentation efforts. Both research and practice have adapted agile methods for the development of innovations, mostly by extending the Stage-Gate process with agile elements [20]. Research has shown that the use of agile elements within innovation management has a positive impact on the overall development performance, reducing the number of customer complaints, improving product quality and increasing the chances of success for the project [20]. Cooper, the inventor of the Stage-Gate models, now also includes many elements of agile development in his more recent models and characterizes this new process as a "more agile, vibrant, dynamic, flexible gating process that is leaner, faster and more adaptive and risk-based" [10].

We were interested in seeing what kind of innovation process models our partner innovation firms used and analyzed their procedures. We observed three different distinct innovation approaches: the service design approach, the innovation lab approach and the lean startup approach. It is important to note that these approaches follow the previously assumed development stages indicated in Figure 2. Every project starts with the identification of opportunities, which is followed by the generation and evaluation of ideas and concludes with concept development and testing. The exact design of the individual stages, however, differs between the three approaches (Figure 4): 

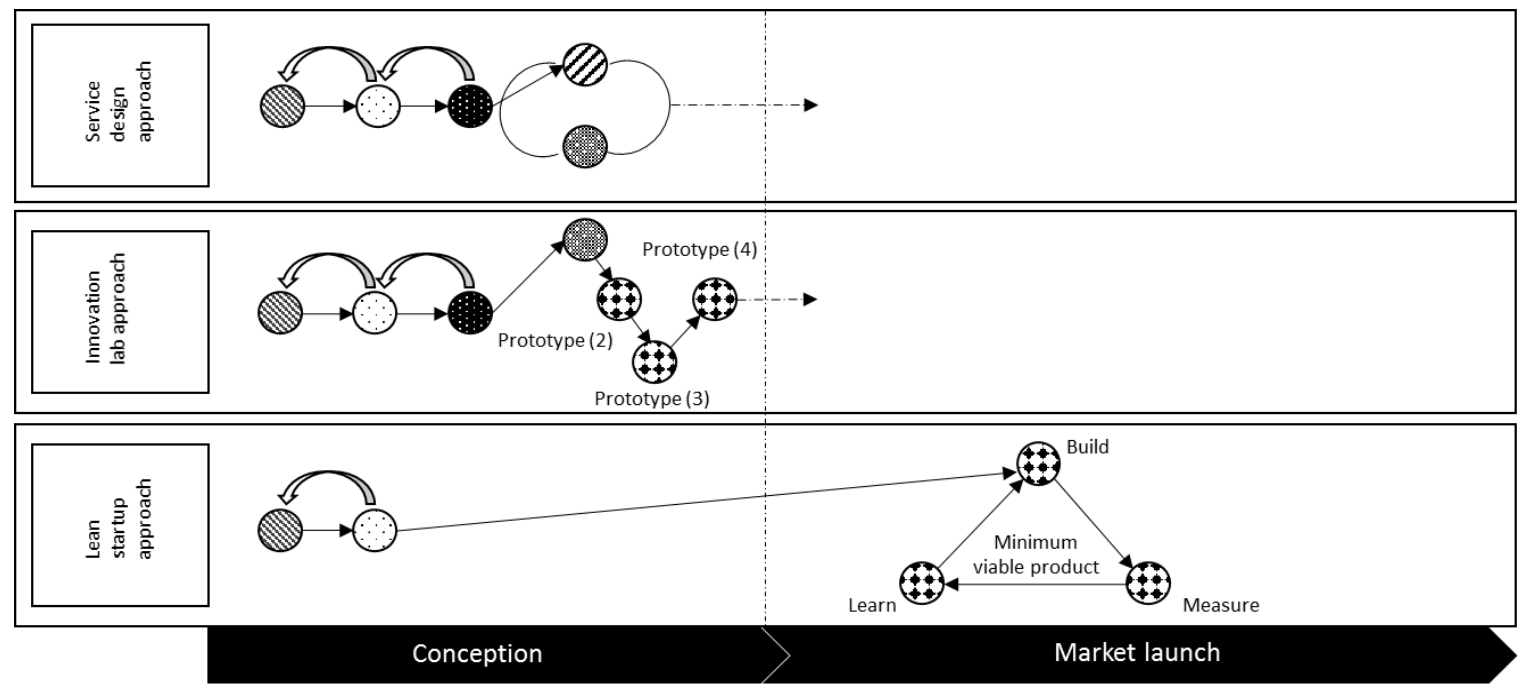

Figure 4. Overview of innovation approaches

- Service design approach: With this approach, only the conception of DVAS proceeds in an iterative setting. A prototype is developed according to the previously derived assumptions and is then used to test the assumptions with selected test users. Based on user feedback, a revision and adaptation of the conceptual design takes place. The prototype is adapted accordingly and re-tested. A previously selected idea is further optimized into a finalized service product.

- Innovation lab approach: In this approach, the ideation as well as the conception stage proceeds in an iterative setting. Only certain main assumptions underlying an idea are conceptualized and then transferred into a first rough prototype with certain functionalities. The subsequent tests are conducted together with selected end-users that focus only on testing the main functionalities of the prototype. Depending on the outcome of the tests, the primary idea will be refined, unsuitable assumptions are adapted or the idea will be rejected.

- Lean startup approach: In contrast to the two previously described approaches, concept development and testing is skipped in this approach. Instead, a previously generated idea is immediately converted into a marketable service; however, only the most substantial functions are implemented in the initial phase. This first version is often called a minimum viable product (MVP). Later, the MVP is tested under real market conditions. The findings of these tests are used to improve the product incrementally. Further functionalities and ideas are implemented on a stepby-step basis.

Each of the innovation approaches mentioned above shares many characteristics of agile development approaches from the field of software development. First, all approaches are structured in an iterative way, whereby each single step is proceeded with in several loops. New insights and findings that are recognized in later development stages are considered to improve and optimize the outcome of the project. Second, these approaches are far less formal and restrictive than conventional Stage-Gatebased innovation approaches, making them faster and more flexible. Third, particularly in the cases of the innovation lab and lean startup approaches, new ideas can be transformed into simplified but realistic service products and can be immediately tested in a real-market setting. This leads to our second recommendation:

R2: Firms should use innovation process models that incorporate agile development principles. Concrete options are the service design approach, the innovation lab approach and the lean startup approach.

\subsection{Opportunity Identification}

The development of an innovation begins with the identification of a promising opportunity, which can be defined as "[a] business or technology gap, that a company or individual realizes, that exists between the current situation and an envisioned future in order to capture competitive advantage, respond to a threat, solve a problem, or ameliorate a difficulty" [14]. The search for opportunities is often influenced by the strategic innovation orientation of a company. This orientation determines under which premises a company approaches innovation projects. Innovation researchers have described two main approaches: a market-oriented, external perspective (market pull) 
and a technology-oriented, internal orientation (technology push) [21]. According to the market-pull approach, new opportunities for innovations mainly arise from the external market. Customer needs are the most important factors for the development of innovations. Understanding and analyzing unmet customer needs is a crucial task in this first step of the innovation process. Companies must apply a wide variety of qualitative and quantitative techniques to detect these needs [4]. Commonly used methods include lead-user interviews, focus groups, observations or large-scale customer surveys. In contrast to the market-oriented approach, companies that follow a technology-push approach induce innovations based on internal capabilities and research. An important trigger for innovations in this context are newly developed technologies or the recombination of existing technologies. Such innovations are usually driven by a company's internal research and development department. Neither of the two approaches performs have been shown to be superior and their usage often depends on the firm's industry or history [4]. In some cases, firms attempt to integrate both approaches.

When studying our case partners, we noticed that all innovation consulting firms invest heavily in the identification of opportunities. In two of the cases, customer needs are the primary starting point of the analysis. Consequently, a market-pull approach was applied. All other cases adopt a more integrated approach, examining customer needs as well as new technologies as reference points for opportunity identification. Interestingly, no innovation consulting firm used a pure technology-push approach. Overall, three main sources are used to identify new opportunities for DVAS:

1) Opportunities from customer needs are identified along the customer journey: Customers and their needs play a crucial role in opportunity identification. This implies that DVAS are developed from the perspective of the customer. For this purpose, innovation consulting firms apply methods such as customer journey mapping by modeling the end-to-end relationship to the customer as a "journey" that spans across different phases and touchpoints of the buying process. Each stage and each touchpoint are compared to particular customer needs. This comparison allows the identification of gaps where the customer experience could be improved or extended through DVAS.

2) Opportunities in related markets are found outside the actual core market of the client. For example, in the case of the development of an innovative new marketing touchpoint for a pharmaceutical company, the innovation consulting firm analyzed different state-of-the-art marketing offerings in various unrelated market areas in order to understand new ways of reacting to the changing communication behavior of customers. This knowledge derived from other markets was not directly related to the core offering but still could be used to develop various opportunities for a new communication platform.

3) Opportunities from new technologies: New technological trends are an equally important source for the development of DVAS. However, innovation consulting firms do not usually develop new technologies on their own but rather use existing technologies from their clients in order to implement new DVAS. In one of the cases we studied, iBeacons were used to implement an indoor navigation solution for airports. Hence, the regular and systematic screening of different technologies allows innovation consulting firms to decide which technological trends should be considered as a potential "enabler" for the development and implementation of new DVAS.

In conclusion, our data showed that innovation consulting firms use an integrated approach when searching for new opportunities for DVAS. In most of the cases, however, customer needs were just the starting point of this discovery. In our cases, technological opportunities were aligned with customer needs first before they were considered as an enabler for DVAS. Consequently, we formulate the following recommendation:

R3: Firms should employ an integrated approach to opportunities identification that exploits new technological opportunities and covers the entire customer journey.

\subsection{Ideation}

After identifying opportunities, the next step in the innovation process is to generate a variety of promising ideas that address the opportunity. However, various studies have shown that only a fraction of initially generated ideas become commercially successful innovations and the number of ideas necessary for one successful innovation differs widely. While some studies claim that $60 \%$ of all projects for implementing an innovative idea do not reach the launch stage, others hold that firms need to consider 50 product ideas or more to end up with one successful product [8]. These numbers lead directly to the question where innovative ideas should originate. According to the "technology push" approach discussed above, new ideas for innovative products evolve primarily within a company. Internal research and development departments as well as the 
marketing function can play an important role in the generation of new ideas. However, more and more companies today are opening their innovation processes to attain additional knowledge from diverse sources outside the company. The involvement of other stakeholders in the innovation process has received extensive attention in the context of "open innovation".

We also examined whether the concept of open innovation applied to the ideation stage of DVAS development. All of the innovation consulting firms we surveyed agreed that the stage of ideation is a crucial step during the development of DVAS. The innovation-consulting firms try to stimulate creativity in order to generate various innovative and relevant ideas. These firms claim that their corporate cultures are an important factor contributing to the success of idea generation. In order to encourage the creative potential of all their employees and to develop a culture of creativity, many such firms conduct ideation sessions on a regular basis. Even so, the activity of ideation in the cases we analyzed was mostly performed in an unstructured way. Ideation for DVAS rarely followed a predefined and systematic approach. Rather, new ideas mostly originated from discussions among different experts. Each innovation consulting firm emphasized the composition of the teams as a far more important success factor and, consequently, all employed interdisciplinary teams with members from various functional and industry backgrounds as well as from different hierarchical levels.

The creative potential was not only limited to employees of the innovation consulting firms. The majority of the surveyed innovation consulting firms actively integrate the client in the idea generation process. They conduct several co-creation workshops in which the innovation consulting firms and the client work together to generate ideas for digital value-added services. Nevertheless, despite this element of client integration, the ideation process is based primarily on internal sources and contrary to our assumptions, a direct involvement of end-users in the ideation process could not be observed in any of the cases. The reasons for this might be twofold. First, for external innovation consulting firms, it might be more cumbersome to get in touch with their clients' customers than for the companies themselves. Second, customers are known to rarely be able to express their ideas appropriately because they are not familiar enough with the present technological opportunities as well as the economic feasibility of their ideas [26]. This leads us to the following recommendation:
R4: Primarily focus on internal sources for idea generation and carefully align ideas with internal stakeholders and clients.

In the next step of the ideation process, all collected or generated ideas need to be evaluated in terms of relevance, target conformity and feasibility. With the previous challenges of idea identification in mind, the decision about which of them to pursue is not less of a challenge. In many cases, companies lack the necessary information or have to rely on inaccurate assumptions for an assessment of the different ideas. There are manifold undesirable consequences, such as companies offering more service than customers want or at price levels that do not reflect the value of the service to customers. Hence, for the successful development of DVAS, it is crucial to select only those ideas that provide customers with a real added value and offer a long-term business impact. This, however, is easier said than done and often fails due to unstandardized or inappropriate evaluation schemas. In turn, the implementation of a more formalized evaluation process and the use of appropriate evaluation criteria can help to speed up the selection process and improve the effectiveness of idea evaluation and the quality of the selection decision. Even if there are no generally accepted criteria for assessing new ideas, main principles for the assessment are often centered on strategic fit, technical feasibility, customer acceptance, market opportunity and financial result [6].

When looking at our partner innovation consulting firms, most of them see the evaluation of ideas as an individual step in the development process of DVAS. Only when using the lean startup approach are the generated ideas tested directly under real market conditions and therefore skip the evaluation phase. All other innovation consulting firms have implemented specific criteria for the selection and prioritization of previously generated ideas. The criteria comprise one or several of the following: financial criteria, strategic criteria, feasibility of the idea and utility for customers. While none of the innovation consulting firms used all categories simultaneously, all of them used at least two different categories for their idea evaluation. Customer utility was used by all companies and therefore appears to be the most important single criterion.

The interviewed innovation consulting firms, however, stated that it was challenging to quantify the potential of new DVAS ideas because most of the assumptions are unknown or difficult to operationalize. Hence, the innovation consulting firms refrained from using complex quantitative approaches, such as the net present value method and 
instead used qualitative approaches. For final decision-making, qualitative analysis and the close cooperation and consolidation of the clients and external experts are used to make final decisions. Based on this, we recommend:

R5: Firms should focus on customer value first but use a multi-criteria scheme for the evaluation of generated ideas.

\subsection{Conception}

Following a positive assessment, some ideas are developed into detailed concepts, which specify ideas into a "well-defined form, including both a written and visual description, that includes its primary features and customer benefits combined with a broad understanding of the technology needed" [14]. Concepts are more than an idea and in contrast to the former, they can be operationalized [9].

The testing and evaluation of the developed concept is an important final step in the front-end development phase and comprises the evaluation of "whether a prospective user (1) understands the idea of the proposed service, (2) reacts favorably to it and (3) feels it offers benefits that answer unmet needs" [19]. In this step, the previous assumptions for the design of the individual components of the concept are tested with respect to the needs of the future endusers. Consequently, the concept must already be presented in a form that permits a test in a real-life environment. Prototypes are frequently used here, making them an important part in the context of service development for two reasons. First, prototypes provide a good illustration of the intangible components of a service. For example, various scenarios of the intended service process can be modeled and tested with prototypes. Second, prototypes provide all of the team members with a common language for discussion. This discussion is important as the development of services becomes increasingly complex as diverse teams or stakeholders outside the original project team often participate in the development process [3]. While prototypes are employed in many fields today, we analyzed whether and how innovation consulting firms employed prototypes in the conception phase for developing DVAS.

Our results showed that, in contrast to some models in innovation research, in which concept development and concept testing are viewed as two independent and consecutive activities, we found that both activities can be seen as an integrated and iteratively performed activity. Furthermore, prototypes serve as a central link between both phases. In the majority of the cases we examined, individual elements of the concept are immediately transferred and tested on the basis of prototypes. The findings from these tests are used to improve and refine the concept. After several iterative loops, this process eventually results in a validated concept that can be commercialized. In one of the cases, however, assumptions from the ideation phase were directly transferred to a simplified but marketable version of the DVAS. This transfer allows the testing of several assumptions under real market conditions and refines the respective version of the digital service accordingly. Consequently, using this so-called "minimum viable product" test allows the conception step to be skipped in order to implement an idea very fast and under real market conditions. Innovation consulting firms that use prototypes in the conception stage do not just apply this methodology to test the concept with future end-users. Three of our partner firms considered prototypes a suitable and transparent way to present their work results to the clients. Prototypes also served as a common basis for discussion in order to refine assumptions or develop suggestions for improvement together with the clients. Prototypes helped enable and improve internal communication between the different project members. They provided a common language for and understanding of communication and thus facilitated cooperation between different areas of competence. Based on our results, we recommend:

R6: Firms should employ prototypes to generate, evaluate and refine the conception of the supporting service as well as to communicate development results to internal stakeholders.

\section{Conclusion and Implications}

The purpose of our research was to gain insights into the fuzzy front-end phase of DVAS development by identifying the best practices from innovation consultancies and test their applicability for firms that seek to develop DVAS on their own. We first provided a classification framework of DVAS. Firms can use this framework as a blueprint for evaluating potential options and changes to their current offer by using DVAS. We then analyzed several development projects from innovation consulting firms that develop DVAS for other companies. We compared our empirical results with existing research from the innovation literature as well as other sources from practice. Based on this comparison, we derived six recommendations that are valuable for other researchers and practitioners alike.

Based on our results, we emphasize four overarching findings. First, we recommend firms to use a similar kind of project structure that innovation consulting 
firms apply, comprising the functions account management, project management, strategy, user experience and technology. Second, also for DVAS, which are often less complex than the core products and services themselves, innovation processes should rely on agile development with interdisciplinary teams. Owing to their higher flexibility, agile development methods appear to be an excellent way to handle the underlying market and technological uncertainties that are often present in the development processes. Third, for the identification and selection of ideas, companies should first focus on the potential utility for customers and mirror such benefits with other technological and economic boundaries to evaluate the feasibility of their ideas. Firms should integrate customers early in DVAS development but also know the limits of such processes. In particular, customers might not be able to evaluate ideas along the entire set of criteria that is relevant for firms, especially since DVAS need to be closely connected to the actual core products or services. Therefore, firms should develop suitable multi-criteria measures to evaluate ideas in a structure manner. Fourth, when it comes to refining ideas and transforming those into concepts, firms should use prototypes, which are also helpful to communicate and discuss preliminary results with internal stakeholders. If time to market matters substantially, they can also employ a MVP that already shows the main functionality of the service, so that it can be developed further into a complete product.

We hope that our insights will help firms improve the development of DVAS and support them in exploiting the full potential of recent technological advances to expand their core offering and provide customers with a better experience. DVAS projects can also constitute an important pillar of corporate digital transformation strategies [17] and should be closely aligned with those.

\section{References}

[1] AT Kearney, and Efma, "Banking in a Digital World", 2013, retrieved May 02, 2019, from https://www.atkearney.de/documents/856314/3998533/Ban king+in+a+digital+world.pdf/44829263-4c00-4925-ae059fc $37217 \mathrm{~d} 6 \mathrm{bb}$

[2] Baines, T., Lightfoot, H., Benedettini, O., and Kay J. M., "The Servitization of Manufacturing", Journal of Manufacturing Technology Management, 20(5), 2009, pp. 547-567.

[3] Blomkvist, J., Conceptualising Prototypes in Service Design, Department of Computer and Information Science, Linköpings Universitet, Linköping, 2011.
[4] Brem, A., and Voigt, K.-I., "Integration of Market Pull and Technology Push in the Corporate Front End and Innovation Management - Insights from the German Software Industry", Technovation, 29(5), 2009, pp. 351367.

[5] Bullinger, A., Innovation and Ontologies: Structuring the Early Stages of Innovation Management, Gabler, Wiesbaden, 2009.

[6] Carbonell-Foulquié, P., Munuera-Alemán, J.-L., and Rodríguez-Escudero, A. I., "Criteria Employed for Go/NoGo Decisions when Developing Successful Highly Innovative Products", Industrial Marketing Management, 33(4), 2004, pp. 307-316.

[7] Chester, A., Lorenz, J. T., Straub, M., and Stüer, C., "The Hidden Benefits of Value-added Services in Commercial Lines Insurance", 2019, retrieved May 05, 2019, from https://www.mckinsey.com/industries/financialservices/our-insights/the-hidden-benefits-of-value-addedservices-in-commercial-lines-insurance

[8] Christensen, C., and Ryanor, M., The Innovator's Solution: Creating and Sustaining Successful Growth, Harvard Business School Press, Boston, 2003.

[9] Clark, G., Johnston, R., and Shulver, M., "Exploiting the Service Concept for Service Design and Development", in: Fitzsimmons, J. A. and Fitzsimmons, M. J. (Eds.), New Service Development: Creating Memorable Experiences, Sage Publications, London, 2000, pp. 71-91.

[10] Cooper, R. G. "The Latest View: The Stage-Gate System for New-Product Development", 2015, retrieved May 05, 2019, from http://www.bobcooper.ca/images/files/ articles/2/2-2-The- Latest-View-on-Stage-Gate.pdf

[11] Cooper, R. G., and Kleinschmidt, E. J., "Determinants of Timeliness in Product Development", Journal of Product Innovation Management, 11(5), 1994, pp. 381-396.

[12] Dornberger, U., and Suvelza, A., "Managing the Fuzzy Front-End of Innovation", 2012, retrieved May 02, 2019, from http://www.sept.uni-leipzig.de/fileadmin/ user_upload/in4in/iN4iN_Fuzzy_Front_End_Innovation_E nglishbook_download_Dornberger_Suvelza.pdf.

[13] Heinze, J., and Matt, C., "Reducing the Service Deficit in M-Commerce: How Service-Technology Fit Can Support Digital Sales of Complex Products", International Journal of Electronic Commerce, 22(3), 2018, pp. 386-418. [14] Koen, P. A., Ajamian, G. M., Boyce, S., Clamen, A., Fisher, E., Fountoulakis, S., Johnson, A., Puri, P., and Seibert, R., "Fuzzy Front End: Effective Methods, Tools, and Techniques", in: Belliveau, P., Griffin, A., and Somermeyer, S. (Eds.), The PDMA Toolbook for New Product Development, John Wiley \& Sons, Hoboken, 2002, pp. 5-36.

[15] Legner, C., Eymann, T., Hess, T., Matt, C., Böhmann, T., Drews, P., Mädche, A., Urbach, N., and Ahlemann, F., "Digitalization: Opportunity and Challenge for the Business and Information Systems Engineering Community", Business \& Information Systems Engineering, 59(4), 2017, pp. 301-308.

[16] Lenfle, S., and Loch, C., "Lost Roots: How Project Management Came to Emphasize Control Over Flexibility and Novelty", California Management Review, 53(1), 2010, pp. 32-55. 
[17] Matt, C., Hess, T., and Benlian, A., "Digital Transformation Strategies", Business \& Information Systems Engineering, 57(5), 2015, pp. 339-343.

[18] Neely, A., "Exploring the Financial Consequences of the Servitization of Manufacturing", Operations Management Research, 1(2), 2008, pp. 103-118.

[19] Scheuing, E. E. and Johnson, E. M., "A Proposed Model for New Service Development", Journal of Services Marketing, 3(2), 1989, pp. 25-34.

[20] Sommer, A. F., Hedegaard, C., Dukovska-Popovska, I., and Steger-Jensen, K., "Improved Product Development Performance Through Agile/Stage-Gate Hybrids: The Next-Generation Stage-Gate Process?", Research Technology Management, 58(1), 2015, pp. 34-45.

[21] Spanjol, J., Qualls, W. J., and Rosa, J. A., "How Many and What Kind? The Role of Strategic Orientation in New Product Ideation", Journal of Product Innovation Management, 28(2), 2011, pp. 236-250.
[22] Tynan, C., and McKechnie, S., "Experience Marketing: A Review and Reassessment", Journal of Marketing Management, 25(5-6), 2009, pp. 501-517.

[23] Verworn, B., Herstatt, C., and Nagahira, A., "The Fuzzy Front End of Japanese New Product Development Projects: Impact on Success and Differences between Incremental and Radical Projects", R\&D Management, 38(1), 2008, pp. 1-19.

[24] Weber, A., Haas, M., and Scuka, D., "Mobile Service Innovation: A European Failure", Telecommunication Policy, 35(5), 2011, pp. 469-480.

[25] Yin, R. K., Case study research: Design and methods (5 ${ }^{\text {th }}$ Ed.), Sage Publications, Los Angeles, 2014.

[26] Zheng Zhou, K., Yim, C.-K., and Tse, D. K., "The Effects of Strategic Orientations on Technology- and Market-Based Breakthrough Innovations", Journal of Marketing, 69(2), 2005, pp. 42-60.

\section{Appendix}

\begin{tabular}{c|ccccc} 
Attribute & $\begin{array}{c}\text { Innovation } \\
\text { consultancy A }\end{array}$ & $\begin{array}{c}\text { Innovation } \\
\text { consultancy B }\end{array}$ & $\begin{array}{c}\text { Innovation } \\
\text { consultancy C }\end{array}$ & $\begin{array}{c}\text { Innovation } \\
\text { consultancy D }\end{array}$ & $\begin{array}{c}\text { Innovation } \\
\text { consultancy E }\end{array}$ \\
\hline Founding year & 1991 & 1990 & 1991 & 1997 & 1995 \\
\hline Employees & $>400$ & $>8000$ & $>310$ & 2555 & 1800 \\
\hline $\begin{array}{c}\text { Customer } \\
\text { segments }\end{array}$ & $\begin{array}{c}\text { Automobile, } \\
\text { health, aviation, } \\
\text { financial }\end{array}$ & $\begin{array}{c}\text { Automobile, } \\
\text { production, } \\
\text { retail, aviation }\end{array}$ & $\begin{array}{c}\text { Aviation, tele- } \\
\text { communication, } \\
\text { retail, food }\end{array}$ & $\begin{array}{c}\text { Telecommuni- } \\
\text { cation, pharma, } \\
\text { food }\end{array}$ & $\begin{array}{c}\text { Automobile, } \\
\text { transport, } \\
\text { financial, retail }\end{array}$ \\
\hline $\begin{array}{l}\text { Interviews } \\
\text { conducted }\end{array}$ & $\begin{array}{c}1 \text { management, } \\
1 \text { strategy, } \\
1 \text { technology }\end{array}$ & $\begin{array}{c}2 \text { management, } \\
2 \text { strategy, } \\
2 \text { design, } \\
1 \text { project } \\
\text { management }\end{array}$ & $\begin{array}{c}\text { 1 strategy, } \\
1 \text { design, } \\
1 \text { project } \\
\text { management }\end{array}$ & $\begin{array}{c}1 \text { management, } \\
1 \text { strategy, } \\
1 \text { technology }\end{array}$ & $\begin{array}{c}1 \text { technology, } \\
1 \text { project } \\
\text { management }\end{array}$ \\
\hline
\end{tabular}

\section{Appendix 1. Overview of innovation consultancies and interviews conducted}

\begin{tabular}{|c|c|c|c|c|c|}
\hline Attribute & Case A & Case B & Case C & Case D & Case $\mathrm{E}$ \\
\hline Core business & Automobile & Flight & Airport & Pharmaceuticals & Financial services \\
\hline Transaction type & B2C & B2C & B2C & $\mathrm{B} 2 \mathrm{C} / \mathrm{B} 2 \mathrm{~B}$ & B2C \\
\hline Purpose of DVAS & $\begin{array}{l}\text { Information, } \\
\text { decision support }\end{array}$ & $\begin{array}{l}\text { Information, } \\
\text { transaction and } \\
\text { decision support, } \\
\text { entertainment }\end{array}$ & Information & $\begin{array}{l}\text { Information, } \\
\text { decision support, } \\
\text { communication }\end{array}$ & Information \\
\hline Relevant phases & Pre-sales phase & $\begin{array}{c}\text { Pre-sales phase, } \\
\text { Use phase }\end{array}$ & Use phase & $\begin{array}{l}\text { Pre-sales phase, } \\
\text { use phase, after- } \\
\text { sales phase }\end{array}$ & Information \\
\hline Observed object(s) & $\begin{array}{l}\text { Development of } \\
\text { several DVAS }\end{array}$ & $\begin{array}{l}\text { Development of } \\
\text { several DVAS }\end{array}$ & $\begin{array}{l}\text { Development of } \\
\text { one DVAS }\end{array}$ & $\begin{array}{l}\text { Development of } \\
\text { several DVAS }\end{array}$ & $\begin{array}{l}\text { Development of } \\
\text { one DVAS }\end{array}$ \\
\hline
\end{tabular}

\section{Appendix 2. Overview of DVAS development projects}

